\title{
REVISÃO SISTEMÁTICA DA LITERATURA SOBRE DEMOCRACIA ELETRÔNICA E GOVERNO ELETRÔNICO
}

Mariana Pessini Mezzaroba

Mestra e doutoranda no Programa de Pós Graduação em Engenharia e Gestão do Conhecimento da Universidade Federal de Santa Catarina na área de Engenharia do Conhecimento. E-mail: marianamezzaroba@yahoo.com.br

Clerilei Aparecida Bier Professora Titular na graduação e pós Graduação do Centro de Ciências da Administração e Socioeconômicas - ESAG -Universidade do Estado de Santa Catarina - UDESC. E-mail: clerilei.bier@udesc.br

\section{Resumo}

O presente artigo busca, por meio de uma revisão sistemática da literatura, responder a seguinte pergunta de pesquisa: Quais são os métodos utilizados em artigos que contenham as palavras e-democracy e e-government e quais os conceitos destes temas? Para a seleção dos artigos utilizou-se a base de dados Scopus, com as palavras-chave e-democracy AND e-government e o filtro temporal de publicaçôes a partir dos anos 2000 até o mês de Junho de 2015. Através de filtros foram selecionados dez artigos que compóe a amostra deste estudo. Após a análise pode-se perceber que o conceito de governo eletrônico é razoavelmente uniformizado, enquanto que o mesmo não acontece com a definição de democracia eletrônica. Além disso, pode-se afirmar que os artigos são principalmente baseados em métodos qualitativos e que são mais escassos a abordagem de pesquisas aplicadas. As poucas referências encontradas evidenciam o espaço e a necessidade de novas pesquisas que possam aprofundar, principalmente, o estudo de iniciativas e experiências de governo e democracia eletrônica.

\section{Palavras-chave}

Democracia Eletrônica; E-democracy; Governo Eletrônico; E-government; Revisão sistemática.

\section{Abstract}

This article aims, through a systematic literature review, answer the following research question: What are the methods used in articles containing the words e-democracy 
and e-government and which concepts of these issues? To select the articles used the Scopus database with the keywords AND e-democracy e-government and the temporal filter publications from the 2000s until the month of June 2015. Through filters were selected ten articles that compose the sample of this study. After the analysis it can be seen that the concept of e-government is fairly uniform, while the same is not true of the definition of electronic democracy. In addition, it can be said that the articles are mostly based on qualitative methods which are more scarce the approach of applied research. The few references found evidence the space and the need for further research that could strengthen mainly the study of initiatives and experiences of government and electronic democracy.

\section{Key words}

Eletronic Democracy; E-democracy; Electronic Government; E-government; Systematic review.

\section{Introdução}

A ampliação do acesso da população à Tecnologias de Informação e Comunicação (TICs) cria oportunidades para a aproximação do Estado com seus principais stakeholders ao mesmo tempo em que são demandas novas formas de acesso à informação e aos serviços públicos. Nesse sentido, o uso das (TICs) pelo governo federal ganhou ênfase com inciativas voltadas para a administração pública, a sociedade, o setor privado e, principalmente ações voltadas para o cidadão. Desde o ano 2000 a administração pública federal passou a trabalhar o conceito de governo eletrônico no Brasil com o objetivo de instituir novas formas de interação eletrônica criando políticas, normas e diretrizes para o tema.

As Tecnologias da Informação e Comunicação estão sendo largamente utilizadas porque permitem a eficiência e a transparência governamental, porém elas não devem se restringir a oferta de serviços, e sim, levar em consideração as necessidades reais dos cidadãos, melhorando a prestação de serviços e a disponibilização de informações essenciais. Neste contexto, ainda pouco se sabe sobre a aplicabilidade e a eficiência de ferramentas para a democracia eletrônica e o governo eletrônico. Desta forma esta pesquisa pretende fazer uma revisão sistemática da literatura na tentativa de encontrar quais são os métodos e técnicas utilizados em artigos referentes a este tema e o que os trabalhos selecionados abordam sobre democracia eletrônica e governo eletrônico.

Nos dias de hoje podemos contar com milhares de iniciativas do governo dispostas de forma on-line para o cidadão. Por isso, com a evolução das TICs começaram a surgir os "programas de Governo Eletrônico através do ideal de governo democrático, sem limites espacial e temporal, ou seja, o Governo para todos, a qualquer hora de qualquer lugar”, 
(CARVALHO, ROVER, 2011, p. 75). As TICs tornaram-se instrumentos importantes no desenvolvimento de ferramentas que buscam a melhoria na prestação de serviços e informaçóes dispostas ao cidadão.

Segundo Rover (2008), levando em consideração as mudanças importantes na forma de organização do Estado e do Direito, contando nesse caso com a participação do cidadão na política, é possível dispor de formas mais globalizadas e dinâmicas de administração através da chamada rede de informação, a Internet. Esta pode assumir um papel fundamental para controlar e fiscalizar a administração pública, como também desburocratizar a relação entre Estado e cidadãos.

Para Mezzaroba (2008, p. 47), "nenhuma governança pode ser construída sem que haja um circuito de comunicação, ou melhor, sem que haja um espaço de circulação de informação". A democracia digital ou eletrônica que surge por meio da evoluçáo das novas tecnologias, implica em inclusão digital, portanto, é necessário o desenvolvimento de políticas que reconheçam um novo direito - o direito a rede, tornando esse direito real e fundamental. Rover (2008) argumenta que hoje a Internet é uma boa mídia para a participação política do cidadão, pois acaba ajudando as pessoas de todo o mundo a se envolverem mais com o governo. $\mathrm{O}$ autor explica ainda que o governo eletrônico acaba sendo uma infraestrutura de rede compartilhada por diversos órgãos de onde a gestão dos serviços públicos é realizada. O objetivo dessa ação é melhorar o atendimento do governo em relação ao cidadão, consequentemente aplicando a transparência nas suas açôes.

Essa nova modalidade de democracia, chamada eletrônica, digital ou em rede, destaca-se pelo voto eletrônico, pela participação on-line dos cidadãos, pelos processos de informação e prestação de contas e também pelos processos de consulta e interação com os representantes políticos. Nesse sentido, Berger et al., (2010, p. 61) destacam a necessidade de difundir o uso de ferramentas digitais, pois elas têm o poder de conectar o cidadão em tempo real. Para os autores, o governo possui papel fundamental na comunicação e interação com o cidadão: "a principal função do governo em rede não é informar, mas sim assegurar a participação dos cidadãos (inclusão digital), pois só assim haverá um verdadeiro Estado democrático de direito".

$\mathrm{Na}$ mesma linha, Santos (2011) destaca que é preciso transformar as iniciativas de governo eletrônico atualmente disponíveis, no sentido de criar mais espaços para a participação efetiva do cidadão, garantindo que todos tenham condições de participar do acesso a tecnologia sabendo utilizá-la.

O futuro na sociedade da informação vai exigir mudanças importantes na organização do Estado e do Direito, como cita Rover (2008) ao afirmar que teremos um Direito e um Estado mais globalizados e dinâmicos, sem perder de vista o local, defendendo a propriedade intelectual e a participação dos cidadãos na política. 


\section{Democracia Participativa e Transparência na Administração Pública e o Governo Eletrônico}

Diante as transformaçóes do Estado e da Gestão Pública e as demandas da sociedade, observa-se que os governos têm se esforçado para "modernizar" a Administração Pública. Em resposta a essa demanda contemporânea, estão sendo introduzidas modificaçóes operacionais nos governos, com uso intensivo das TICs, trazendo a Internet, como instrumento de transparência, controle social e accountability.

A tecnologia permite a eliminação de fronteiras, uma vez que pessoas de todo mundo podem se conectar e realizar trocas de informaçóes através de recursos tecnológicos. A possibilidade de conexão entre pessoas e informaçóes cresceu significativamente em poucos anos, e o número de usuários da rede mundial tem crescido de forma exponencial - O Brasil conquistou a $7^{\text {a }}$ posição no mercado mundial de internet, com 46,3 milhôes de visitantes de 15 anos ou mais que acessam a rede mundial pelo computador de casa ou do trabalho, o que representa aumento de $16 \%$ em relação a 2010 . "Em toda a América Latina, o público da internet atingiu 129,3 milhóes em dezembro de 2011. As informaçôes são do estudo "2012 Brazil Digital Future in Focus", da comScore." (www. webexpoforum.com.br/tag/comscore).

O desenvolvimento de novas tecnologias com a consequente ampliação do acesso da população à internet eleva sobremaneira o "potencial transformador das atividades sociais e econômicas, uma vez que a estrutura e a dinâmica dessas atividades inevitavelmente serão, em alguma maneira, afetadas pela infraestrutura de informaçóes disponível e tem ainda marcante dimensão social, em virtude de seu elevado potencial de promover a integração, ao reduzir as distâncias entre pessoas e aumentar o seu nível de informação". (TAKAHASHI, 2000, p.5)

A evolução das inovaçóes tecnológicas e das redes na gestão da administração pública, seus impactos na promoção da transparência e participação cidadã em ordem a incentivar globalmente práticas governamentais de acesso público à informação e controle social, são mecanismos necessários para o fortalecimento das capacidades institucionais e de gestão pública.

Segundo COELHO (2001), "No âmbito governamental verificamos que os processos de reforma e modernização da gestão pública estão enfrentando um novo desafio, qual seja, o de adaptarem-se à crescente difusão das inovaçóes tecnológicas e à expansão de um novo paradigma produtivo associado ao estabelecimento da chamada sociedade do conhecimento. Neste sentido, com o intuito de promover uma maior utilização das Tecnologias da Informação e de Comunicação (TIC), por parte das administraçóes públicas, diversos governos criaram programas para a implantação da Sociedade da Informação, onde por meio de um documento chamado Livro Verde, propóem diretrizes para a 
estruturação de infraestruturas de comunicação, regulação, educação e universalização de acesso ao ambiente digital, bem como para o desenvolvimento de açóes governamentais que também promovam o incremento da sua eficiência e da sua transparência, por meio do uso intensivo destas tecnologias".

TINOCO (2001) entende que "O acesso à informação de boa qualidade é um pré -requisito para o exercício da cidadania, vale dizer, condição essencial para que os problemas socioeconômicos sejam debatidos e resolvidos no convívio democrático entre os grupos sociais". Sem informação, o indivíduo exerce mal seus direitos, sobretudo o mais importante deles, que é o voto.

No moderno contexto de democratização das sociedades tem havido uma crescente mobilização no sentido de que os administradores públicos ampliem a transparência sobre as suas açóes. Objetivando dar respostas concretas a essa demanda contemporânea, estão sendo introduzidas modificações operacionais nos governos, com uso intensivo da Tecnologia da Informação e da Internet. Esse conjunto de açóes tem sido denominado de Governo Eletrônico.

O conceito usual de governo eletrônico, segundo Gartner Group (2000) apud Santos e Honorífica (2002, p.6), é: “a contínua otimização de oferta de serviço, participação do eleitorado e governança mediante transformação de relacionamentos internos e externos com uso da tecnologia, da internet e da nova mídia”.

No entanto, cabe ressaltar que o governo eletrônico não está vinculado somente à utilização das Tecnologias da Informação e da Internet, pois, de acordo com Prado (2009, p.32), "os governos sempre fizeram uso, em maior ou menor escala, das tecnologias disponíveis em seus processos internos ou na interação com a sociedade", transformando o conceito de governo eletrônico muito mais extenso, como o aumento da eficiência, monitoramento das políticas públicas, transparência, busca da melhor governança, aplicação das TICs para melhorar os processos da administração pública, dentre outros.

No Brasil, mais de 4.000 sites governamentais na Internet, reunidos na Rede Governo, oferecem cerca de 700 diferentes tipos de serviços e prestam um volume considerável de informaçóes ao cidadão. O Portal da Rede Governo (www.redegoverno.gov.br) é a entrada virtual para todas as páginas oficiais brasileiras disponibilizadas na Internet, eliminando a necessidade de anotar milhares de endereços públicos na rede mundial de computadores ou a necessidade do usuário entrar várias vezes nas páginas iniciais e menus de ministérios, fundaçôes, agências ou autarquias.

Agune e Carlos (2005, p.1) conceituam governo eletrônico da seguinte forma: "Governo Eletrônico, ao contrário do que o nome pode a princípio sugerir, significa muito mais do que a intensificação do uso da tecnologia da informação pelo Poder Público. Em verdade, ele deve ser encarado como a transição entre uma forma de governar 
fortemente segmentada, hierarquizada e burocrática, que ainda caracteriza o dia-a-dia da imensa maioria das organizaçóes públicas e privadas, para um Estado mais horizontal, colaborativo, flexível e inovador, seguindo um figurino mais coerente com a chegada da sociedade do conhecimento, fenômeno que começou a ganhar contornos mais visíveis no último quarto do século passado". Neste sentido, é que se pode afirmar que uma das metas a ser atingida para a construção de uma nova governabilidade democrática é difundir e incentivar globalmente práticas governamentais como transparência orçamentária, acesso público à informação e participação social.

A participação direta do cidadão na gestão pública é princípio consolidado há quase cinquenta anos, inscrito na própria Declaraçáo dos Direitos do Homem, na qual se lê que "todo homem tem o direito a tomar parte no governo de seu país diretamente ou por intermédio de representantes livremente escolhidos” (art. XXI, inciso I).

Todavia, poucas constituiçóes reproduziram o conteúdo desse dispositivo, sendo que a brasileira o fez apenas em 1988: "todo poder emana do povo, que o exerce por meio de representantes eleitos ou diretamente, nos termos desta Constituição" (Art. 1º, par. Único). Silva esclarece que o "princípio participativo caracteriza-se pela participação direta e pessoal da cidadania na formação dos atos de governo" (2008, p.141), sendo que as primeiras manifestaçóes de democracia participativa mesclavam instrumentos de participação direta e indireta tais como: a iniciativa popular (art. 14, III da CF/88), o referendo popular (art. 14, II da CF/88), o plebiscito (art. 14, I da CF/88) e a ação popular (art. 5, LXXIII da CF/88).

Nesse sentido a Constituição Federal reconhece o exercício direto da democracia lançando as bases para a instituição e consolidação de uma efetiva democracia participativa no Brasil. O mandamento constitucional tem aspecto abrangente uma vez que a República é formada pela união indissolúvel dos Estados e Municípios e do Distrito Federal, irradiando a recomendação, com base nos princípios da descentralização político-administrativa, para todos os entes públicos, que devem promover um reordenamento político-institucional de modo a garantir o efetivo exercício da democracia participativa nas decisóes de caráter público, reconhecendo-se, assim, o papel indispensável da participação da comunidade nas decisóes que afetam a sua própria realidade, em especial àquelas diretamente ligadas às políticas públicas (Beçak, 2008, p. 5932).

Desde o momento em que, a partir da Constituição de 1988 consagrou-se o princípio da participação popular nas políticas públicas e criaram-se diversos sistemas descentralizados e participativos de gestão das políticas sociais, instaurou-se o debate entre diversas forças políticas e sociais sobre as relaçóes entre os mecanismos e práticas da democracia direta e participativa e os tradicionais mecanismos de exercício da democracia representativa (Raichelis, 2000). 
Neste diapasão é que o Governo Eletrônico, operacionalizado pelos portais eletrônicos - disponibilizando serviços e informaçôes aos cidadãos, possibilitaria maior transparência, controle social e accountability. Tais pressupostos instigam a necessidade de desenvolver uma infraestrutura nacional de dados abertos que permita a viabilização do accountability e a democratização dos processos.

Vale destacar que accountability não é apenas uma questão de desenvolvimento organizacional ou de reforma administrativa. Entende-se que a simples criação de mecanismos de controle burocrático não se tem mostrado suficiente para tornar efetiva a responsabilidade dos servidores públicos (Vieira, 2008). Assim a accountability significa a obrigação que todos têm de responder por terem assumido uma responsabilidade e, refere-se ao controle que os poderes estabelecidos exercem uns sobre os outros (accountability horizontal), mas também à necessidade que os representantes têm de prestar contas e submeter-se ao julgamento da população (accountability vertical) (Campos, 1990).

Sem embargo esta responsabilidade para ser efetiva deve ser abordada desde uma perspectiva em que a matriz teórica privilegie a dicotomia entre estado e sociedade civil, partilhando da ideia de que o controle da sociedade sobre a ação governamental constitui uma especificidade e merece uma distinção à parte das perspectivas de accountability vertical ou horizontal, e é neste sentido que envereda a discussão da accountability societal (Carneiro, 2004).

Apresentando a noção de accountability societal, Smulovitz e Peruzzotti (2000, p. 7) a definem como um mecanismo de controle não eleitoral, que emprega ferramentas institucionais e não institucionais (açôes legais, participação em instâncias de monitoramento, denúncias na mídia etc), que se baseia na ação de múltiplas associaçôes de cidadãos, movimentos, ou mídia, objetivando expor erros e falhas do governo, trazer novas questóes para a agenda pública ou influenciar decisóes políticas a serem implementadas pelos órgãos públicos.

Nas concepções mais modernas de sociedades democráticas se aceita como natural e espera-se que os governos e o serviço público sejam responsáveis perante os cidadáos. Neste sentido, a accountability deve ser compreendida como uma questáo de democracia, pois quanto mais avançado o estágio democrático, maior o interesse pela accountability.

No tópico introdutório buscou-se abordar a importância do governo e da democracia eletrônica para as sociedades, com ênfase na correlação direta entre transparência da administração pública e participação social na gestão e a construção de uma nova governabilidade democrática.

$\mathrm{Na}$ sequência apresentam-se os procedimentos e os resultados desta pesquisa, que busca elaborar uma revisão sistemática da literatura para identificar trabalhos realizados 
a partir do ano de 2000 que abordem a questão da e-democracia ${ }^{1}$ e do e-governo ${ }^{2}$ na base de dados Scopus, uma das maiores bases de literatura científica revisada por pares da atualidade. O objetivo é o de analisar as técnicas e métodos científicos utilizados nos 10 (dez) artigos que entraram no escopo desta pesquisa e trazer os conceitos de Democracia Eletrônica e Governo Eletrônico, abordados por seus autores.

\section{Procedimentos Metodológicos}

Para realizar a pesquisa sobre o tema optou-se por desenvolver uma revisão sistemática, que tem por fundamento ser metódica e explícita. Segundo Sampaio e Mancini (2007), boas revisóes sistemáticas são recursos importantes para descobrir o que está sendo falado sobre determinado assunto devido ao acelerado processo da informação científica. Este tipo de estudo serve para nortear o desenvolvimento de projetos, indicando novos rumos para futuras investigaçóes e identificando quais métodos de pesquisa foram utilizados em uma área. Ou seja, a investigação sistemática abre a possibilidade para que outros pesquisadores executem novamente a pesquisa, podendo chegar a resultados iguais ou até mesmo divergentes.

Para iniciar uma pesquisa sistemática é necessário definir o objetivo da revisão, identificar a literatura que será pesquisada e selecionar os estudos que serão incluídos. Nesta pesquisa optou-se por escolher a base de dados Scopus para delimitar os artigos a serem analisados. Para a realização da revisão sistemática da literatura foram definidas cinco etapas estratégicas:

a) quanto à formulação da pergunta de pesquisa e das palavras-chave.

b) quanto à justificativa da base de dados utilizada para a pesquisa, e aos filtros utilizados.

c) quanto à análise bibliométrica estabelecendo critérios de inclusão e exclusão de artigos.

d) quanto à apreciação dos registros selecionados de acordo com a abordagem dos trabalhos.

e) quanto ao término da revisão sistemática da literatura, por meio da elaboração das consideraçôes sobre os métodos utilizados no tema pesquisado com base na análise dos registros selecionados.

1 E-democracia também será trabalhada no texto como democracia eletrônica tendo sempre o mesmo significado.

2 E-governo também será trabalhado no texto como governo eletrônico tendo sempre o mesmo significado. 
Para realizar a primeira etapa desta pesquisa respondeu-se a seguinte questão base: Quais são os métodos utilizados em artigos que contenham as palavras e-democracy e e-government e quais os conceitos destes temas? Na visão geral do artigo se tomou como premissa analisar o tipo de abordagem; as técnicas de levantamento de dados e a definiçáo dado pelos autores sobre os temas de Governo Eletrônico e Democracia Eletrônica. Em seguida, foram delimitadas as palavras-chave para a pesquisa: "e-democracy AND e-government”. Após essas definiçóes partiu-se para a etapa de busca na base de dados e a definiçãao dos filtros que seriam utilizados. A escolha pela base de dados Scopus deve-se pelo fato de esta plataforma ser um dos maiores bancos de resumos e referências bibliográficas da atualidade revisada por pares.

Determinou-se que para este trabalho todas as áreas propostas pela base Scopus eram relevantes e abrangiam o tema da pesquisa. Como filtro delimitou-se a escolha temporal a partir do ano 2000, pois se considerou que o início das iniciativas de governo e democracia eletrônica datam deste período, levando em consideração o caso brasileiro. Há que se ressaltar que a base de dados Scopus é uma plataforma indexada na língua inglesa, mas abrange estudos relevantes publicados em qualquer idioma.

\section{Resultado e Análise da Pesquisa}

Nesta seção serão abordados os procedimentos finais de escolha dos artigos selecionados para a pesquisa e o resultado encontrado em cada um deles tendo como base os métodos, a abordagem e as definiçóes dos temas utilizados pelos autores dos mesmos.

Como último filtro, foram selecionados dez registros para a análise geral. A pesquisa preocupa-se em delimitar trabalhos que contenham as palavras e-democracry e e-government no título. Sete dos 200 artigos encontrados com as palavras-chave continham as duas palavras no título e foram escolhidos para análise. Os outros três trabalhos foram delimitados pela pertinência, pois eram os primeiros registros mais relevantes segundo a Scopus e possuíam link para dowloand do arquivo completo em PDF. Cabe ressaltar que o primeiro artigo registrado na base de dados náo estava disponível e, em uma busca mais aprofundada na web descobriu-se que era um artigo que deveria ser comprado para se ter acesso completo. Dessa forma, o artigo foi excluído da delimitação desta pesquisa, passando assim, para os próximos que continham ou a palavra e-democracy ou a palavra e-government no título.

Utilizando as palavras-chave: e-democracy AND e-government, e selecionando como filtro o ano de 2000 até os dias de hoje (Junho de 2015) obteve-se na busca uma relação de $200 \operatorname{artigos}^{3}$. As áreas de maior concentração de artigos encontrados foram

3 Pesquisa realizada no dia 11 de junho de 2015. No site: www.scopus.com 
Computer Science (114); Social Sciences (91); Business Management and Accounting (45); Decision Sciences (22) e Engineering (13), destacando-se que o mesmo artigo pode ser classificado em mais de uma área. Dos 200 artigos encontrados no banco de dados 195 eram em Inglês, dois em Espanhol, um em Chinês, um em Português e um Turco. As palavras-chave da pesquisa apareceram da seguinte forma com o número de artigos entre parênteses: E-democracy (112); E-government (77); E-Government (70); Government data processing (70); Information technology (25). Veja a Tabela 1 referente ao ano e a quantidade de registros publicados.

\section{Tabela 1 - Resultado por ano de publicação com a palavra-chave "e-democracy AND e-government"}

\begin{tabular}{|c|c|c|c|}
\hline $\begin{array}{c}\text { ANO DE } \\
\text { PUBLICAÇÃO }\end{array}$ & $\begin{array}{c}\text { QUANTIDADE } \\
\text { DE REGISTROS } \\
\text { PUBLICADOS }\end{array}$ & $\begin{array}{c}\text { ANO DE } \\
\text { PUBLICAÇÃO }\end{array}$ & $\begin{array}{c}\text { QUANTIDADE } \\
\text { DE REGISTROS } \\
\text { PUBLICADOS }\end{array}$ \\
\hline 2000 & 0 & 2008 & 11 \\
\hline 2001 & 1 & 2009 & 24 \\
\hline 2002 & 6 & 2010 & 27 \\
\hline 2003 & 5 & 2011 & 23 \\
\hline 2004 & 22 & 2012 & 15 \\
\hline 2005 & 23 & 2013 & 2 \\
\hline 2006 & 21 & 2014 & 27 \\
\hline 2007 & 6 & 2015 & 24 \\
\hline
\end{tabular}

Fonte: Elaborado pelos autores (2015) a partir da base Scopus.

Selecionou-se após a análise do conteúdo encontrado no campo de busca dez artigos que apresentavam as palavras e-democracy e e-government. Os três primeiros artigos encontrados foram considerados os mais relevantes de acordo com os filtros da pesquisa e continham uma ou outra palavra no título relacionada ao tema de busca. Os outros sete foram selecionados neste trabalho, pois abordavam as duas palavras-chave no título, tendo assim maior relevância de conteúdo para a pesquisa proposta. A Tabela 2, a seguir, demonstra os artigos que foram selecionados após a análise de conteúdo e enfoque. 


\section{Tabela 2 - Resultado da estratégia de busca para revisão sistemática da literatura}

\begin{tabular}{|c|c|c|c|}
\hline ARTIGO & AUTOR & ANO & PERIÓDICO \\
\hline $\begin{array}{l}\text { 1. An e-democracy } \\
\text { experience: Digital cabinet } \\
\text { office of rio grande do sul } \\
\text { state (Brazil) }\end{array}$ & $\begin{array}{l}\text { Macadar, M.A., } \\
\text { Pereira, G.V., } \\
\text { Daniel, V.M. }\end{array}$ & 2012 & $\begin{array}{l}\text { ACM International } \\
\text { Conference Proceeding } \\
\text { Series, pp. 385-388. }\end{array}$ \\
\hline $\begin{array}{l}\text { 2. Open government } \\
\text { and e-government: } \\
\text { Democratic challenges from } \\
\text { a public value perspective }\end{array}$ & $\begin{array}{l}\text { Harrison, T.M., } \\
\text { Guerrero, S., } \\
\text { Burke, G.B., } \\
\text { Cook, M., } \\
\text { Cresswell, A., } \\
\text { Helbig, N., } \\
\text { Hrdinova, J., } \\
\text { Pardo, T. }\end{array}$ & 2012 & $\begin{array}{l}\text { Information Polity } 17 \\
(2), \text { pp. 83-97. }\end{array}$ \\
\hline $\begin{array}{l}\text { 3. E-government website } \\
\text { evaluation with hybrid } \\
\text { MCDM method in fuzzy } \\
\text { environment }\end{array}$ & $\begin{array}{l}\text { Burmaoglu, S., } \\
\text { Kazancoglu, Y. }\end{array}$ & 2012 & $\begin{array}{l}\text { International Journal } \\
\text { of Applied Decision } \\
\text { Sciences } 5 \text { (2), pp. 163- } \\
181 .\end{array}$ \\
\hline $\begin{array}{l}\text { 4. Is e-government a } \\
\text { way to e-democracy? A } \\
\text { longitudinal study of the } \\
\text { Iranian situation }\end{array}$ & $\begin{array}{l}\text { Kardan, A.A., } \\
\text { Sadeghiani, A. }\end{array}$ & 2011 & $\begin{array}{l}\text { Government } \\
\text { Information Quarterly } \\
28(4) \text {, pp. 466-473. }\end{array}$ \\
\hline $\begin{array}{l}\text { 5. Analysis on how to } \\
\text { enhance e-democracy } \\
\text { through e-government }\end{array}$ & Guo, Y. & 2011 & $\begin{array}{l}\text { International } \\
\text { Conference on } \\
\text { Management and } \\
\text { Service Science, MASS } \\
\text { 2011, art. no. } 5999004 .\end{array}$ \\
\hline $\begin{array}{l}\text { 6. Testing the Development } \\
\text { and Diffusion of } \\
\text { E-Government and } \\
\text { E-Democracy: A Global } \\
\text { Perspective }\end{array}$ & $\begin{array}{l}\text { Lee, C.-P., Chang, } \\
\text { K., Berry, F.S. }\end{array}$ & 2011 & $\begin{array}{l}\text { Public Administration } \\
\text { Review } 71 \text { (3), pp. } 444- \\
454 .\end{array}$ \\
\hline $\begin{array}{l}\text { 7. E-government". } \\
\text { Not e-governance' Not } \\
\text { e-democracy not now! } \\
\text { Not ever? }\end{array}$ & Norris, D.F. & 2010 & $\begin{array}{l}\text { ACM International } \\
\text { Conference Proceeding } \\
\text { Series, pp. 339-346. }\end{array}$ \\
\hline
\end{tabular}




\begin{tabular}{|l|l|l|l|}
\hline \multicolumn{1}{|c|}{ ARTIGO } & \multicolumn{1}{|c|}{ AUTOR } & ANO & \multicolumn{1}{c|}{ PERIÓDICO } \\
\hline $\begin{array}{l}\text { 8. The impact of } \\
\text { electronic government on } \\
\text { democracy: E-democracy } \\
\text { through e-participation }\end{array}$ & $\begin{array}{l}\text { Spirakis, G., } \\
\text { Spiraki, C., } \\
\text { Nikolopoulos, K. }\end{array}$ & 2010 & $\begin{array}{l}\text { Electronic Government } \\
7 \text { (1), pp. 75-88. }\end{array}$ \\
\hline $\begin{array}{l}\text { 9. Mind the gap': } \\
\text { e-Government and } \\
\text { e-democracy }\end{array}$ & Kolsaker, A., Lee- & 2006 & $\begin{array}{l}\text { Lecture Notes in } \\
\text { Artificial Intelligence } \\
\text { and Lecture Notes in } \\
\text { Bioinformatics) 4084 }\end{array}$ \\
$\begin{array}{l}\text { (including subseries } \\
\text { I0. E-government and } \\
\begin{array}{l}\text { E-democracy in Latin } \\
\text { America }\end{array}\end{array}$ & Padget, J. & $\begin{array}{l}\text { Lecture Notes in } \\
\text { Computer Science }\end{array}$ \\
\hline
\end{tabular}

Fonte: Elaborado pelos autores (2015) a partir da base Scopus.

Macadar, Pereira e Daniel (2012) no artigo An e-democracy experience: Digital cabinet office of rio grande do sul state (Brazil) é um trabalho realizado pela Pontifícia Universidade do Rio Grande de Sul e apresenta um estudo de caso do Gabinete Digital do Rio Grande do Sul (Brasil) onde o principal objetivo é identificar a influência dos fatores institucionais e a implementação de práticas de e-democracia utilizando a Teoria Institucional como referencial teórico. Na seção 3 do artigo é apresentada a Metodologia classificando a pesquisa como qualitativa que visa compreender um problema examinando um estudo de caso. Foi realizada uma pesquisa de campo para encontrar diferentes facetas no estudo que, contou também, com a análise de documentos que continham informaçôes importantes para o prosseguimento da pesquisa, além de uma entrevista semiestruturada com o diretor executivo do Gabinete Digital. Pode-se se considerar a abordagem coerente, pois se pretendia estudar um fenômeno específico coletando de diversas formas uma quantidade relevante de dados para a composição do trabalho. Segundo a visão dos autores o Governo Eletrônico compreende o uso de Tecnologia da Informação não só para melhorar a gestão de recursos e processos governamentais

(público e-Administration), mas também para atualizar os cidadãos (e-Serviços) e para aumentar a participação democrática dos cidadãos nas práticas dos governos (eDemocracia). Ainda, segundo os pesquisadores, a Democracia Eletrônica se preocupa com a interatividade do ambiente, criando assim, oportunidades de cooperação entre os cidadãos e grupos sociais, tornando cada vez mais política a participação nos processos de tomada de decisão. 
No artigo Open government and e-government: Democratic challenges from a public value perspective, Harrison et al. (2012) discorrem sobre as iniciativas de Governo Aberto na administração de Barack Obama trabalhando o tema qualitativamente e trazendo marcos teóricos essenciais que temporalizam as açóes de transparência, participação e colaboração em governos. A pesquisa pode ser considerada como científica, pois apresenta através de um estudo teórico os avanços nessa área propondo um marco conceitual para orientar os formuladores de políticas no desenvolvimento do Governo Aberto através do Governo Eletrônico. O artigo propóe um quadro que formaliza e explicita o "valor público" representando informaçôes, programas e benefícios que tem o objetivo de servir os interesses da população em meio eletrônico, um dos princípios fundamentais do Governo Eletrônico. Os autores apresentam uma visão separada de e-governo e e-democracia, o primeiro, segundo eles é fortemente ligado em esferas administrativas e o segundo é ligado à política, mas agora com o surgimento do Governo Aberto (Open Government) as duas esferas de atividades devem trabalhar em conjunto.

Em: E-government website evaluation with hybrid MCDM method in fuzzy environment, Burmaoglu e Kazancoglu (2012) apresentam uma pesquisa aplicada em sites de governo eletrônico de um grupo de países da União Europeia e, relatam sobre como a lógica Fuzzy é utilizada na avaliação de processos. Na pesquisa obteve-se uma formação de critérios que utilizam dois tipos de números fuzzy, combinando dois métodos MCDM (Múltiplos Critérios de Tomada de Decisão), aplicando assim a metodologia para a avaliação de problemas em sítios governamentais. $\mathrm{O}$ artigo se relaciona com a área de Engenharia e Gestão do Conhecimento, pois afirma que os portais de governo tem papel importante no conhecimento da sociedade melhorando o compromisso cidadão junto à democracia, considerando o cidadão como cliente e fazendo a satisfação deste como meta final. O tema trabalhado de forma aplicada foi coerente no caso, já que poucas pesquisas nesta área se preocupam em produzir conteúdo científico através de análise quantitativa. Conforme os autores, é necessário avaliar sites de Governo Eletrônico levando em conta muito além das características de web design, e-serviços e e-democracia.

$\mathrm{O}$ artigo Is e-government a way to e-democracy? A longitudinal study of the Iranian situation de Kardan e Sadeghiani (2011) apresenta as semelhanças entre os conceitos de governo eletrônico e democracia eletrônica para avaliar como estas iniciativas estão sendo utilizadas no Iran. A pesquisa faz um estudo longitudinal utilizando dois métodos diferentes: uma revisão sistemática baseada em uma lista de verificação e um questionário de pesquisa, chegando a conclusão de que a ênfase em e-governo e em e-democracia não é recomendada em países como o Iran. O estudo se faz coerente já que os autores trabalham primeiramente de forma qualitativa as açóes de governo eletrônico no país, para depois apresentar os resultados obtidos através de entrevistas e questionários. Todo o processo de formulação das perguntas e de como o questionário foi aplicado está descrito 
no artigo, considerando assim, o método e as técnicas utilizadas adequadas para análise do tema proposto. Em relaçáo às definiçóes dos dois temas, os autores ressaltam que em muitos casos os termos de governo eletrônico e democracia eletrônica estão sendo usados de forma vaga, sem alavancar os benefícios que as TICs podem trazer nas relaçóes entre governo e cidadáos. Os autores definem o e-governo como sendo o uso de informação e comunicação em todos os aspectos das operaçôes de uma organização do governo. Já a edemocracia, segundo os pesquisadores, é o uso de tecnologias e estratégias de informação e comunicação pelos setores democráticos dentro dos processos políticos das comunidades locais, estados / regiôes, nações e no cenário global.

De que forma o e-governo pode aumentar a e-democracia é o assunto principal do artigo intitulado Analysis on how to enhance e-democracy through e-government de Guo (2011). A pesquisa teórica parte de uma revisão de literatura para definir e-governo e edemocracia apresentando cinco maneiras de como o governo eletrônico pode aumentar a democracia eletrônica entre elas: melhorando o acesso à informação e serviços públicos; aumentando a responsabilidade dos governos e dos cidadáos e aprofundando a participaçâo dos cidadãos no processo democrático. $\mathrm{O}$ trabalho não se detém a estudar de forma estatística o enlace entre e-democracia e e-governo, porém pode ser considerado adequado ao caso já que se sabe da dificuldade em quantificar as pesquisas nesta área principalmente por serem relativas a casos tão teóricos. As definiçôes trabalhadas pelos autores parecem ser bem pertinentes perante aos temas abordados, em que, segundo eles, o Governo Eletrônico é definido como uma forma de os governos utilizarem as tecnologias de comunicaçáo, em especial aplicaçôes de Internet baseados na web para proporcionar aos cidadáos e às empresas um acesso mais conveniente a informaçóes e serviços do governo, para melhorar a qualidade dos serviços e para proporcionar maiores oportunidades de participar de instituiçóes e processos democráticos. Além disso, os pesquisadores classificam a e-democracia como sendo a informatizaçáo do discurso político, com o objetivo de aumentar, aperfeiçoar e aprofundar a participação dos cidadãos nos processos políticos e de tomada de decisóes do governo através de um espectro de atividades de campanhas eleitorais, voto, consulta e participação no processo político, pesquisas de opinião pública, e de comunicação e troca entre eleitos e eleitores.

Testing the Development and Diffusion of E-Government and E-Democracy: A Global Perspective de Lee, Chang, e Berry (2011) traz um estudo empírico que analisa os fatores associados com o nível relativo de desenvolvimento do e-governo e e-democracia em 131 países. Os autores conseguiram modelar quatro hipóteses neste estudo onde a política de mudança, as normas políticas, a competição e a pressão dos cidadãos são fortemente ligadas à naçôes em que a política de governo eletrônico é avançada. A pesquisa empírica avalia as determinantes de governo eletrônico e democracia eletrônica separadamente, apresentando quatro modelos teóricos sobre o tema. O estudo qualitativo é bastante denso 
apresentando conteúdos relevantes sobre as temáticas propostas, sendo coerente com objetivo inicial da pesquisa. Os autores trabalham com a ideia de que o governo eletrônico é o uso de tecnologias de informação e comunicação (TIC) e sua aplicação por parte do governo para a prestação de informaçóes e serviços públicos para o povo. A questão da democracia eletrônica é definida pelos pesquisadores também como sendo o uso das TICs, mas com o objetivo de proporcionar o acesso dos cidadãos à informação e conhecimento sobre o processo político e as escolhas.

Norris (2010) no artigo intitulado E-government** Not e-governance * Not e-democracy not now! Not ever? fornece através de literatura e experiência empírica, a definição para governo eletrônico, que, segundo ele, é a mera disponibilização de serviços e informaçóes por meio eletrônico. $\mathrm{O}$ autor deixa claro que e-governo não é e-democracia nem e-governança, mas que através do uso das Tecnologias da Informação e Comunicação espera-se produzir uma mudança fundamental nesta área. $\mathrm{O}$ artigo faz um resgate sobre governo eletrônico e como este serviço seguiria em direção à democracia eletrônica analisando outras pesquisas empíricas de governos americanos que definem o e-governo e, por fim, relaciona os temas às Tecnologias da Informação e Comunicação. Analisando dados quantitativos em portais de governo eletrônico, no decorrer da pesquisa o autor consegue explorar de forma mais ampla o tema proposto que se considera adequado ao trabalho nesta área. Quanto a e-democracia, segundo o autor, não existe uma definição única ou universalmente aceita do termo existente atualmente na literatura, porém o tema diz respeito a: e-participação, democracia virtuais, teledemocracia, democracia digital, democracia cibernética ou e-democracia. Conforme os pesquisadores, poucos escritores têm o cuidado de especificar o que eles querem dizer com estes termos, e pode-se ler obras inteiras sobre e-democracia sem encontrar uma definição desse fenômeno, o que deixa claro a deficiência de uma definiçóes universal para este tópico.

$\mathrm{O}$ artigo The impact of electronic government on democracy: E-democracy through e-participation de Spirakis, Spiraki e Nikolopoulos (2010) descreve as implementaçóes de governo eletrônico que promovem democracia eletrônica através da participação eletrônica (e-participação) trazendo benefícios para os cidadãos, empresas, administração pública e para a sociedade. $\mathrm{O}$ estudo é baseado em uma revisão de literatura e na experiência empírica dos autores trazendo definiçôes importantes sobre os dois temas. Os autores defendem de forma teórica, através de uma revisão de literatura, que a e-democracia é a pedra angular para que o cidadão tenha uma participação efetiva nas questóes públicas, tendo como objetivo a produção de processos funcionais democráticos como a comunicação, o fornecimento de informaçóes e de tomada de decisão após um diálogo público por via eletrônica. Este foi o único artigo analisado que aborda a questão da democracia eletrônica efetiva através da participação eletrônica do cidadão, se fazendo coerente no que foi proposto pelos pesquisadores, mesmo não apresentando dados estatísticos. Sendo 
assim, os pesquisadores definem o Governo Eletrônico como sendo o uso da Tecnologia da Informação e Comunicação na transformação do governo, visando principalmente a melhoria da acessibilidade, eficácia e responsabilidade baseada na difusão da informação e do desenvolvimento de políticas de informação.

A pesquisa 'Mind the Gap': e-Government and e-Democracy, de Kolsaker e Lee-Kelley (2006) analisa as percepçóes, atitudes e comportamentos dos cidadãos buscando apresentar os resultados de um estudo que sugere que os cidadãos percebem o governo eletrônico como sendo um meio de informação e comunicação, porém que não pode ser considerado como um instrumento de participação democrática. Os autores trabalham a pesquisa de forma holística, afastando, segundo eles, a abordagem positivista encontrada em muitos estudos anteriores para explorar a não racionalidade do governo eletrônico. $\mathrm{O}$ tipo de pesquisa é a entrevista por amostragem que foi enviada por envelope para mil residências do Reino Unido, mostrando-se satisfatória ao tema proposto no artigo. Para os autores o Governo Eletrônico tem sido identificado como um meio de reforçar a democracia através do aumento da participação representativa na tomada de decisão política. Por outro lado, segundo eles, o conceito de e-democracia é mal definido e relativamente pouco pesquisado, deixando novamente transparecer a importância de pesquisas que tragam definiçốes neste campo teórico.

Enfim, o último artigo, E-Government and E-Democracy in Latin America, de Padget (2005) pretende apresentar um breve panorama do governo eletrônico na América Latina, relatando casos como o do serviço público no México que foi um dos primeiros atos de governo eletrônico implementado em 1996 através da CompraNet, um canal de bases de concursos públicos e sistema de compras facilitando o desenvolvimento e a implementaçáo de novos projetos. No artigo os autores citam o caso do Brasil no que diz respeito à urna eletrônica (voto eletrônico) juntamente com a ação no país vizinho do Paraguai, porém somente no ano de 2003 com a ajuda do sistema brasileiro de voto já implementado. A agenda Digital do Chile também é citada como evolução de democracia eletrônica, onde o governo chileno realiza uma série de açôes para aumentar o acesso às TICs, como, por exemplo, disponibilizar banda larga de internet aos cidadáos. Os assuntos abordados são de suma relevância, porém pouco explorados pelos autores já que o artigo possui apenas quatro páginas. A pesquisa poderia abordar dados quantitativos dessa relação apresentada nos países da América Latina, expondo de forma mais tangível a realidade encontrada. Além disso, os conceitos de Governo Eletrônico e Democracia Eletrônica não são apresentados no trabalho pelo autor.

\subsection{Análise dos Métodos}

Esta pesquisa busca descrever os métodos de abordagem e os métodos de pesquisa dos 10 (dez) artigos selecionados para análise. As pesquisas científicas podem ter métodos 
de abordagem indutivos (partindo de dados particulares, que inferem uma verdade geral ou universal) e dedutivos (que partem de uma situação geral e genérica para uma particular) como também métodos de pesquisa que podem ser quantitativos e qualitativos.

A pesquisa qualitativa é estruturada em termos do uso de palavras e aplicada para entender como indivíduos ou grupos dão significado a um problema humano ou social. Os dados coletados neste tipo de pesquisa são encontrados no ambiente dos participantes e seguem a linha de raciocínio indutiva com foco na complexidade e interpretação de uma determinada situação. (CRESWELL, 2010).

A pesquisa quantitativa é baseada em dados numéricos que passam a ser analisados por procedimentos estatísticos e no uso de questôes fechadas e pré-determinadas com o objetivo de examinar a relação entre variáveis. Este tipo de pesquisa tem caráter dedutivo em que os dados podem ser generalizados para replicação posterior. (CRESWELL, 2010).

A pesquisa de métodos mistos é a combinação da pesquisa qualitativa e quantitativa num mesmo estudo. Pode ser considerado um tipo completo de estudo já que exige grande esforço por parte do pesquisador que deverá analisar primeiramente dados qualitativos e quantitativos de forma isolada para formular sua teoria. (CRESWELL, 2010). Veja a classificação dos artigos na tabela 3 .

\section{Tabela 3: Artigos e seus Métodos de Abordagem e de Pesquisa}

\begin{tabular}{|l|c|c|}
\hline \multicolumn{1}{|c|}{ ARTIGO } & $\begin{array}{c}\text { MÉTODO DE } \\
\text { ABORDADAGEM }\end{array}$ & $\begin{array}{c}\text { MÉTODO DE } \\
\text { PESQUISA }\end{array}$ \\
\hline $\begin{array}{l}\text { 1. An e-democracy experience: } \\
\text { Digital cabinet office of rio grande } \\
\text { do sul state (Brazil) }\end{array}$ & Indutivo & Qualitativo \\
\hline $\begin{array}{l}\text { 2. Open government and } \\
\text { e-government: Democratic } \\
\text { challenges from a public value } \\
\text { perspective }\end{array}$ & Indutivo \\
\hline $\begin{array}{l}\text { 3. E-government website } \\
\text { evaluation with hybrid MCDM } \\
\text { method in fuzzy environment }\end{array}$ & Dedutivo & Qualitativo \\
\hline $\begin{array}{l}\text { 4. Is e-government a way to } \\
\text { e-democracy? } \text { A longitudinal } \\
\text { study of the Iranian situation }\end{array}$ & Dedutivo & Quantitativo \\
\hline $\begin{array}{l}\text { 5. Analysis on how to enhance } \\
\text { e-democracy through } \\
\text { e-government }\end{array}$ & Indutivo & Misto \\
\hline
\end{tabular}




\begin{tabular}{|l|c|c|}
\hline \multicolumn{1}{|c|}{ ARTIGO } & $\begin{array}{c}\text { MÉTODO DE } \\
\text { ABORDADAGEM }\end{array}$ & $\begin{array}{c}\text { MÉTODO DE } \\
\text { PESQUISA }\end{array}$ \\
\hline $\begin{array}{l}\text { 6. Testing the Development and } \\
\text { Diffusion of E-Government } \\
\text { and E-Democracy: A Global } \\
\text { Perspective }\end{array}$ & Indutivo & Qualitativo \\
\hline $\begin{array}{l}\text { 7. E-government" Not } \\
\text { e-governance' Not e-democracy } \\
\text { not now! Not ever? }\end{array}$ & Dedutivo \\
\hline $\begin{array}{l}\text { 8. The impact of electronic } \\
\text { government on democracy: } \\
\text { E-democracy through } \\
\text { e-participation }\end{array}$ & Indutivo & Misto \\
\hline $\begin{array}{l}\text { 9. 'Mind the gap': e-Government } \\
\text { and e-democracy }\end{array}$ & Qualitativo \\
\hline $\begin{array}{l}\text { 10. E-government and } \\
\text { E-democracy in Latin America }\end{array}$ & Indutivo & Qualitativo \\
\hline
\end{tabular}

Fonte: Elaborada pelos autores (2015).

Os artigos analisados também apresentam conceitos que definem as palavras-chave desta pesquisa: Democracia Eletrônica e Governo Eletrônico. Apesar de possuírem no título uma, outra, ou as duas palavras que destacaram esta análise, alguns não relatavam no texto a definição científica dos temas estudados ou apresentavam outras distinçóes. A Tabela 4 foi criada para explicitar os conceitos abordados nos 10 (dez) artigos escolhidos nesta pesquisa. Foram encontrados conceitos de Democracia Eletrônica; Governo Eletrônico; Governança; Governo Aberto e Participação Eletrônica (e-participação). Os conceitos definidos em cada artigo estão assinalados na tabela que segue:

Tabela 4: Artigos que definem conceitos de Democracia Eletrônica; Governo Eletrônico; Governança; Governo Aberto e Participação Eletrônica

\begin{tabular}{|l|c|c|c|c|c|}
\hline \multicolumn{1}{|c|}{ ARTIGO } & $\begin{array}{c}\text { Democracia } \\
\text { Eletrônica }\end{array}$ & $\begin{array}{c}\text { Governo } \\
\text { Eletrônico }\end{array}$ & Governança & $\begin{array}{c}\text { Governo } \\
\text { Aberto }\end{array}$ & $\begin{array}{c}\text { Participaçáo } \\
\text { Eletrônica }\end{array}$ \\
\hline $\begin{array}{l}\text { 1. An } \\
\text { e-democracy } \\
\text { experience: }\end{array}$ & & & & & \\
$\begin{array}{l}\text { Digital cabinet } \\
\text { office of rio } \\
\text { grande do sul } \\
\text { state (Brazil) }\end{array}$ & $\mathrm{X}$ & $\mathrm{X}$ & & & \\
\hline
\end{tabular}




\begin{tabular}{|c|c|c|c|c|c|}
\hline ARTIGO & $\begin{array}{c}\text { Democracia } \\
\text { Eletrônica }\end{array}$ & $\begin{array}{c}\text { Governo } \\
\text { Eletrônico }\end{array}$ & Governança & $\begin{array}{c}\text { Governo } \\
\text { Aberto }\end{array}$ & $\begin{array}{c}\text { Participação } \\
\text { Eletrônica }\end{array}$ \\
\hline $\begin{array}{l}\text { 2. Open } \\
\text { government and } \\
\text { e-government: } \\
\text { Democratic } \\
\text { challenges from } \\
\text { a public value } \\
\text { perspective }\end{array}$ & X & $\mathrm{X}$ & & X & \\
\hline $\begin{array}{l}3 . \\
\text { E-government } \\
\text { website } \\
\text { evaluation with } \\
\text { hybrid MCDM } \\
\text { method in fuzzy } \\
\text { environment }\end{array}$ & & & & & \\
\hline $\begin{array}{l}\text { 4. Is } \\
\text { e-government } \\
\text { a way to } \\
\text { e-democracy?. } \\
\text { A longitudinal } \\
\text { study of the } \\
\text { Iranian situation }\end{array}$ & X & X & & & \\
\hline $\begin{array}{l}\text { 5. Analysis on } \\
\text { how to enhance } \\
\text { e-democracy } \\
\text { through } \\
\text { e-government }\end{array}$ & X & X & & & \\
\hline $\begin{array}{l}\text { 6. Testing the } \\
\text { Development } \\
\text { and Diffusion of } \\
\text { E-Government } \\
\text { and } \\
\text { E-Democracy: } \\
\text { A Global } \\
\text { Perspective }\end{array}$ & X & X & & & \\
\hline $\begin{array}{l}7 . \\
\text { E-government." } \\
\text { Not } \\
\text { e-governance." } \\
\text { Not } \\
\text { e-democracy not } \\
\text { now! Not ever? }\end{array}$ & X & X & $\mathrm{X}$ & & \\
\hline
\end{tabular}




\begin{tabular}{|l|c|c|c|c|c|}
\hline \multicolumn{1}{|c|}{ ARTIGO } & $\begin{array}{c}\text { Democracia } \\
\text { Eletrônica }\end{array}$ & $\begin{array}{c}\text { Governo } \\
\text { Eletrônico }\end{array}$ & Governança & $\begin{array}{c}\text { Governo } \\
\text { Aberto }\end{array}$ & $\begin{array}{c}\text { Participaçáo } \\
\text { Eletrônica }\end{array}$ \\
\hline $\begin{array}{l}\text { 8. The impact } \\
\text { of electronic } \\
\text { government } \\
\text { on democracy: } \\
\begin{array}{l}\text { E-democracy } \\
\text { through } \\
\text { e-participation }\end{array}\end{array}$ & $\mathrm{X}$ & $\mathrm{X}$ & & & \\
\hline $\begin{array}{l}\text { 9. 'Mind the gap': } \\
\text { e-Government } \\
\text { and } \\
\text { e-democracy }\end{array}$ & $\mathrm{X}$ & & & $\mathrm{X}$ \\
\hline $\begin{array}{l}\text { 10. } \\
\text { E-government } \\
\text { and } \\
\text { E-democracy in } \\
\text { Latin America }\end{array}$ & & & & & \\
\hline
\end{tabular}

Fonte: Elaborada pelos autores (2015).

\section{Conclusões}

Os termos governo eletrônico (e-government ou e-governo) e democracia eletrônica (e-democracy ou e-democracia) permitem diversas formas de interpretação por parte dos cidadãos que não estão acostumados com essas novas açôes de governo proporcionadas pelas Tecnologias da Informação e Comunicação. Cabe ressaltar que existem, sim, distinções para essas definições e que uma não complementa a outra, porém as duas formas podem e devem estar conectadas para que as novas açóes de governo e governança por meio digital sejam eficientes.

Dentro deste contexto, ressalta-se que os artigos encontrados evidenciaram diversas definições e formas de abordagens das pesquisas nesta área das Ciências Sociais Aplicadas. A grande maioria apresentou estudo empírico também utilizando a revisão de literatura para embasar os temas de governo e democracia eletrônica. É importante frisar que após delimitação das palavras-chave foram encontrados somente 125 artigos que continham as palavras e-democracy e e-government no título, resumo ou nas palavras-chave no período dos anos 2000 até junho de 2015. Comparando com outros temas que envolvam as TICs há que se considerar que o número de artigos publicados na plataforma Scopus foi muito abaixo de outros já pesquisados. A carência por pesquisas nesta área, tanto quantitativas quanto qualitativas é sentida tendo esses números como critério de análise. 
Percebe-se que a definição de Governo Eletrônico (e-governo) é pertinente em todas as pesquisas e há poucas distinções de conceitos. Já uma carência encontrada diz respeito à definição de Democracia Eletrônica (e-democracia) que, segundo a análise desta pesquisa está sendo pouco trabalha e difundida em trabalhos científicos. Dentre os 10 (dez) artigos analisados apenas um trabalhava a questão da democracia eletrônica ligada à participação popular.

Conforme já descrito na introdução desta pesquisa, acredita-se que o pleno desenvolvimento de uma democracia realizada por meio eletrônico deva passar, necessariamente, pela participação dos cidadãos de forma on-line, através de sítios e portais que ofereçam serviços de qualidade e de fácil acesso, até mesmo para o cidadão mais leigo no assunto. Os conteúdos disponibilizados de forma on-line devem ser trabalhados de forma a fornecerem informaçóes claras ao usuário, fortalecendo a acessibilidade dos mesmos à toda a população. Os processos de consulta e interação devem ser aprimorados por parte do governo e difundidos de forma a serem mais procurados pela população, que pode e deve cobrar de seus governantes também pela Internet.

Neste sentido, os autores defendem que o massivo uso das Tecnologias da Informação e Comunicação na Administração Pública como instrumento de transparência, de controle social e accountability são mecanismos necessários para o fortalecimento das capacidades institucionais e de gestão pública, permitindo novas formas democráticas e aumentando a responsabilidade tanto por parte do governo na divulgação das informações da gestão, quanto por parte dos cidadãos na sua fiscalização.

No Brasil, o modelo atual de Estado tem enfrentado dificuldade em solucionar os principais problemas que afetam a nossa sociedade. Isso nos leva à necessidade de redefinição de estratégias de articulação das políticas públicas, a instauração de diversos programas reformistas e o fortalecimento modelos de gestáo pública, onde se priorize o fortalecimento de uma cidadania ativa, na qual o cidadão, portador de direitos e deveres, é essencialmente criador de direitos para abrir novos espaços de participação política. E a administração pública, por sua vez, deve incentivar e coordenar tais processos a fim de fortalecer a democracia. Açóes de governo eletrônico devem facilitar o exercício da cidadania e consequentemente o aperfeiçoamento da democracia. Como já comentado, a mera disponibilização de informaçôes por parte do governo em meio eletrônico não é o bastante, se faz necessária a inclusão digital do cidadão e políticas que garantam a interatividade deste com o governo, construindo assim, o que se denomina de democracia eletrônica, com participação cidadã, instigada pelo aumento da transparência, controle social e accountability. Sendo assim, a avaliação do desempenho do governo eletrônico juntamente com a democracia eletrônica se faz necessária, na tentativa de garantir que direitos estão sendo passados e apresentados aos cidadãos. 
Deve-se ressaltar a importância do levantamento dos processos de gestão do conhecimento nesta área, de forma a propor trabalhos que visem quantificar a qualidade dos serviços prestados pelo governo e o quanto essas açóes estão avançando nas diversas formas governamentais espalhadas pelo mundo.

\section{Referências}

BEÇAK, Rubens. Instrumentos de Democracia Participativa. Manaus: CONPEDI, 2008, p. 5932.

BERGER, Marciele ; MEZZAROBA, Orides ; SANTOS, Paloma Maria. E - Democracia: possibilidades e a experiência brasileira frente aos novos sistemas. In: Orides Mezzaroba e Fernando Galindo (eds.). Democracia Eletrônica. Zaragoza: Prensas Universitarias de Zaragoza, 2010. Lefis Series 11. p. 53-71.

BURMAOGLU S., Kazancoglu Y. E-government website evaluation with hybrid MCDM method in fuzzy environment (2012). International Journal of Applied Decision Sciences, 5 (2), p. 163-181. Disponível em: http://www.inderscience.com/ offer.php?id=46504. Acesso em: 06 jun, 2013.

CAMPOS (1.990), Anna Maria. Accountability: Quando Poderemos Traduzí-la para o Português? Rio de Janeiro/RJ/Brasil, Revista de Administração Pública, Ano 24, $\mathrm{n}^{\circ} 2$, fevereiro-abril; (Carneiro, 2004).

CARNEIRO, Carla Bronzo Ladeira. GOVERNANÇA E ACCOUNTABILITY: ALGUMAS NOTAS INTRODUTÓRIAS. Texto para discussão no 13. Escola de Governo da Fundaçáo João Pinheiro. Belo Horizonte, agosto de 2004.

CARVALHO, Marisa Araújo ; ROVER, Aires José. Comunidades virtuais de prática e os ambientes virtuais colaborativo s nas aplicações do governo eletrônico. In: Nicolás Cabezudo Rodríguez (ed.). Inclusión digital: perspectivas y experiências. Zaragoza: Prensas Universitarias de Zaragoza, 2011. Lefis Series 12, p. 75-104.

COELHO (2001), Espartaco Madureira. Governo Eletrônico e Seus Impactos na Estrutura e na Força de Trabalho das Organizaçóes Públicas. Brasília/Distrito Federal/ Brasil, Revista do Serviço Público, Ano 52, n² 2, abril-junho.

CRESWELL, John W. Projeto de pesquisa: métodos qualitativo, quantitativo e misto.

Tradução Magda Lopes; consultoria, supervisão e revisão técnica desta edição Dirceu da Silva. - 3. Ed. - Porto Alegre: Artmed, 2010. 296p.

DIAS, Claudia. Governo Eletrônico: definiçôes, características, potenciais benefícios e tipos de avaliação. Retirado do II CONeGOV nos anais da Conferência Sul-Americana em Ciência e Tecnologia Aplicada ao Governo Eletrônico, 2005, p. 
101. Disponível em: <http:/www.i3g.org.br/editora/livros/conegov2005anais.pdf> Acesso em: 10 out, 2011.

GUO Y. Analysis on how to enhance e-democracy through e-government. (2011) International Conference on Management and Service Science, MASS 2011, , art. no. 5999004. Disponível em: http://ieeexplore.ieee.org/xpls/abs_all.jsp?arnumber=5999004. Acesso em: 07 jun, 2013.

HARRISON T.M., Guerrero S., Burke G.B., Cook M., Cresswell A., Helbig N., Hrdinova J., Pardo T. Open government and e-government: Democratic challenges from a public value perspective. (2012) Information Polity, 17 (2), p. 83-97. Disponível em: http://dl.acm.org/citation.cfm?doid=2037556.2037597. Acesso em: 06 jun, 2013.

KARDAN A.A., Sadeghiani A. Is e-government a way to e-democracy?. A longitudinal study of the Iranian situation. (2011) Government Information Quarterly, 28 (4), p. 466-473. Disponível em: http://www.sciencedirect.com/science/article/pii/ S0740624X11000578. Acesso em: 07 jun, 2013.

KOLSAKER A., Lee-Kelley L. 'Mind the gap': e-Government and e-democracy. (2006) Lecture Notes in Computer Science (including subseries Lecture Notes in Artificial Intelligence and Lecture Notes in Bioinformatics), 4084 LNCS , p. 96-106. Disponível em: http://link.springer.com/chapter/10.1007\%2F11823100_9. Acesso em: 09 jun, 2013.

LEE C.-P., Chang K., Berry F.S. Testing the Development and Diffusion of E-Government and E-Democracy: A Global Perspective. (2011) Public Administration Review, 71 (3), p. 444-454. Disponível em: http://onlinelibrary.wiley. com/doi/10.1111/j.1540-6210.2011.02228.x/abstract;jsessionid=FA058B575A26357B96F1847BC4F4AF38.d02t02. Acesso em: 08 jun, 2013.

MACADAR M.A., Pereira G.V., Daniel V.M. An e-democracy experience: Digital cabinet office of rio grande do sul state (Brazil). (2012) ACM International Conference Proceeding Series, p. 385-388. Disponível em: http://dl.acm.org/citation. cfm?doid=2463728.2463801. Acesso em: 06 jun, 2013.

MEZZAROBA, Orides. A representatividade política na era da informação e o espaço reservado ao povo. In: Aires José Rover (ed.) Inclusáo Digital e Governo Eletrônico. Zaragoza: Prensas Universitarias de Zaragoza, 2008. Lefis Series 3 p. 39-52.

NORRIS D.F. E-government"' Not e-governance"'- Not e-democracy not now! Not ever? (2010) ACM International Conference Proceeding Series, p. 339-346. Disponível em: http://dl.acm.org/citation.cfm?doid=1930321.1930391. Acesso em: 08 jun, 2013. 
PADGET J. E-government and E-democracy in Latin America. (2005) IEEE Intelligent Systems, 20 (1) , p. 94-96. Disponível em: http://ieeexplore.ieee.org/xpl/articleDetails.jsp?arnumber=1392680. Acesso em: 09 jun, 2013.

RAICHELIS, Raquel “Os Conselhos de gestão no contexto internacional” in: Conselhos Gestores de Políticas Públicas. Revista Pólis, no 37, São Paulo, 2000.

ROVER, A. J. ; SANTOS, P. M. ; FERREIRA, M. V. A. ; BERNARDES, M. B. ; PINTO, C. A.d ; YAMAOKA, E. J ; DE PAULA, G. ; JÚNIOR, E. S. ; ROCZANSKI . Avaliação de portais e sítios governamentais no Brasil. In: Aires José Rover; Fernando Galindo. (Org.). O Governo Eletrônico e suas múltiplas facetas. Zaragoza: Lefis Series, 2010, v. 10, p. 11-38.

ROVER, Aires José ; RUSCHEL, José Airton. Business Intelligence: governo eletrônico na administração da Justiça. In: Fernando Galindo y Aires J. Rover (Eds.). Derecho, gobernanza y tecnologías de la información en la sociedad del conocimiento. Zaragoza: Prensas Universitarias de Zaragoza, 2009. Lefis Series 7, p. 279-298.

ROVER, Aires José. O Governo Eletrônico e a inclusão digital: das faces da mesma moeda chamada democracia. In: Aires José Rover (ed.) Inclusáo Digital e Governo Eletrônico. Zaragoza: Prensas Universitarias de Zaragoza, 2008. Lefis Series 3, p. 11-37.

SAMPAIO R.F, MANCINI M.C. Estudos de revisão sistemática: um guia para síntese criteriosa da evidência científica. In: Rev. bras. fisioter., Sáo Carlos, v. 11, n. 1, p. 83-89, jan./fev. 2007. Disponível em: http://www.scielo.br/pdf/rbfis/v11n1/12.pdf. Acesso em: 02 jun. 2013.

SANTOS, Paloma Maria. Modelagem de processos para disseminação de conhecimento eletrônico via TV Digital. Dissertação (2011). Disponível em: < http://btd. egc.ufsc.br/wp-content/uploads/2011/04/Paloma_Maria_Santos.pdf>. Acesso em: 22 out, 2011.

SANTOS, Roberval de Jesus Leone dos; HONORÍFICA, Mención. Governo Eletrônico: o que se deve e o que não se deve fazer. XVI Concurso de Ensayos y Monografías del CLAD sobre Reforma del Estado y Modernización de la Administración Pública “Gobierno Electrónico”. Caracas, 2002

SMULOVITZ, Catalina e PERUZZOTTI, Enrique (2000) Societal accountability: the other side of control. Mimeo.

SPIRAKIS G., Spiraki C., Nikolopoulos K. The impact of electronic government on democracy: E-democracy through e-participation. (2010) Electronic Government, 7 (1) , p. 75-88. Disponível em: http://www.inderscience.com/offer.php?id=29892. Acesso em: 09 jun, 2013. 
TAKAHASHI, Tadao (Org.). Sociedade da Informação: livro verde. Brasília: Academia Ministério da Ciência e da Tecnologia, 2000.

TINOCO, João Eduardo Prudêncio. Balanço Social: Uma Abordagem da Transparência e da Responsabilidade Pública das Organizaçóes. São Paulo/SP/Brasil, Editora Atlas, 2001.

VIEIRA, Rejane Esther. Accountability, Democracia e a Cidadania Organizada: Uma Análise da Atuação dos Mecanismos de Controle e Transparência na Administração Pública. Disponível em: http://www.artigonal.com/gestao-artigos/accountability-democracia-e-a-cidadania-organizada-uma-analise-da-atuacao-dos-mecanismos-de-controle-e-transparencia-na-administracao-publica-1444418.html. Acesso: 20 mai. 2014. 